\title{
Gold catalysis: helping create a sustainable future
}

\author{
Nikolaos Dimitratos $\cdot$ Jennifer K. Edwards • \\ Christopher J. Kiely • Graham J. Hutchings
}

Received: 28 June 2012/ Accepted: 31 July 2012

(C) The Author(s) 2012. This article is published with open access at Springerlink.com

\begin{abstract}
In recent years there has been a general realisation that supported gold and gold bimetallic nanoparticles can be very effective for a broad range of redox reactions. In this paper we review the preparation of gold palladium nanoparticles using a sol-immobilisation methodology and show their effectiveness for the oxidation of benzyl alcohol and the direct synthesis of hydrogen peroxide.
\end{abstract}

Keywords Gold catalysis - Alcohol oxidation . Hydrogen peroxide synthesis

\section{Introduction}

Gold for many centuries has held a special place in the attention of the general public partly due its intrinsic value but also because of the beautiful jewelry and artwork that can be created from it. The reason for this is that gold is the most noble of metals and consequently is considered immutable. From a chemical perspective, gold has therefore relatively little inherent interest as it appears in its bulk form to have a very limited chemistry. However, a major discovery of the 1980s was that gold, when sub-divided down to the

\footnotetext{
N. Dimitratos

Department of Chemistry, University College London,

20 Gordon Street, London WC1H 0AJ, UK

J. K. Edwards · G. J. Hutchings ( $\square)$

School of Chemistry, Cardiff University, Main Building, Park Place, Cardiff CF10 3AT, UK

e-mail: hutch@cardiff.ac.uk

\section{J. Kiely}

Department of Materials Science and Engineering, Lehigh University, 5 East Packer Avenue, Bethlehem, PA 18015-3195, USA
}

nanoscale, can be highly reactive and can activate small molecules. This has led to an explosion of interest in the chemistry of gold and, in particular, the synthesis and use of small gold-containing nanoparticles as redox catalysts.

On the basis of many studies, Au nanoparticles have been shown to be particularly effective for a broad range of oxidation and hydrogenation reactions as well as chemical synthesis [1-8]. These include the low temperature oxidation of $\mathrm{CO}$ [8], especially when used as part of the processes for purifying a fuel cell feedstock $[9,10]$, the synthesis of vinyl chloride by the hydrochlorination of ethyne [11], the selective oxidation of alkenes to epoxides [12,13] and alcohols to aldehydes [14] as well as selective hydrogenation [15]. Recently, research in our groups has shown that the alloying of Pd with Au can enhance the activity of the nanoparticles, and such materials have been found to be particularly effective for the direct synthesis of hydrogen peroxide from its elemental constituents [16-20] and the oxidation of alcohols [21]. In this paper, we review an aspect of our work concerning the synthesis of supported $\mathrm{Au}-\mathrm{Pd}$ alloy nanoparticles prepared by sol-immobilisation for two important classes of redox reaction; namely the direct synthesis of hydrogen peroxide and the oxidation of benzyl alcohol. These two reactions have very broad interest in the chemical community as they both display key features concerning selectivity control. In the case of hydrogen peroxide synthesis, it is important that the non-selective formation of water is minimised, and in the case of alcohol oxidation to the corresponding aldehyde it is essential that the over-oxidation to the carboxylic acid is minimised. By way of background information, hydrogen peroxide $\left(\mathrm{H}_{2} \mathrm{O}_{2}\right)$ is a major commodity chemical [22] and has significant uses in cleaning and bleaching. At present, $\mathrm{H}_{2} \mathrm{O}_{2}$ is produced using an indirect process which involves the sequential hydrogenation and oxidation of an alkyl anthraquinone, thereby avoiding the 
potential for explosive contact between hydrogen and oxygen to occur [23]. The direct synthesis of hydrogen peroxide is not a reaction that is easy to control, since the formation of water is preferred under all conditions, and the quest to find a suitable catalyst for the direct reaction between $\mathrm{H}_{2}$ and $\mathrm{O}_{2}$ has remained a challenge for almost a century, and as such, it has attracted considerable attention. Supported Pd catalysts have been the focus of much of the research [24-32]. Our work on this topic [16-20] has shown that a combination of $\mathrm{Pd}$ with Au promotes both the activity and the selectivity for the direct $\mathrm{H}_{2} \mathrm{O}_{2}$ synthesis reaction. Furthermore, these catalysts are also very effective for the oxidation of alcohols, and once again the addition of Pd to Au increases both the selectivity and the activity [21]. The link between these two reactions is considered to be at the level of the possible surface intermediates present during the reaction, and it is thought that a surface hydroperoxy species may be responsible for the selective chemistry observed in both processes. In our initial studies [16-20], we used a wet co-impregnation method to prepare gold-palladium nanoparticles and concluded that either homogeneous random alloys or core-shell structures [19] could be formed. Based on this work, we hypothesised that small homogeneous Au-Pd nanoparticles were likely to be the active species in these catalysts and we set out to utilise a sol-immobilisation method [33] in an attempt to 'tailor-make' these nanoparticles. We reasoned that since the volume fraction of these ultra-small alloy particles formed using the co-impregnation method was quite small $[19,20]$, pre-forming colloidal nanoparticles should be more material efficient and hence overcome this problem. We found that this latter method can indeed produce well-defined particle size distributions [33]. However, the catalysts do not retain the selectivity displayed by the catalysts prepared by wet impregnation [16-20]. This paper reviews some of the essential structural features and reactivity traits of $\mathrm{Au}-\mathrm{Pd}$ alloy catalysts prepared using a solimmobilisation method.

\section{A general preparation method for $\mathrm{Au}, \mathrm{Pd}$ and $\mathrm{Au}-\mathbf{P d}$ nanoparticles using sol-immobilisation}

In our studies that are highlighted in this brief review, we have used the following general method for catalyst generation by sol-immobilisation [33]. It presents a facile method of reproducibly forming either mono-metallic or bi-metallic nanoparticles. For the preparation of supported $\mathrm{Au}-\mathrm{Pd}$ colloidal materials, an aqueous solution of $\mathrm{PdCl}_{2}$ (Johnson Matthey) and $\mathrm{HAuCl}_{4} \cdot 3 \mathrm{H}_{2} \mathrm{O}$ (Johnson Matthey) of the desired concentration was prepared. Poly-vinylalcohol (PVA) ( $1 \mathrm{wt} \%$ aqueous solution, Aldrich, MW = $10,000,80 \%$ hydrolyzed) and an aqueous solution of $\mathrm{NaBH}_{4}(0.1 \mathrm{M})$ were also prepared. For example, a catalyst comprised Au-Pd nanoparticles with $1 \mathrm{wt} \%$ total metal loading on a carbon support (Aldrich G60) was prepared as follows: to an aqueous $\mathrm{PdCl}_{2}$ and $\mathrm{HAuCl}_{4}$ solution of the desired concentration, the required amount of a PVA solution $(1 \mathrm{wt} \%)$ was added $[\mathrm{PVA} /(\mathrm{Au}+\mathrm{Pd})(\mathrm{wt} / \mathrm{wt})=$ 1.2]; a freshly prepared solution of $\mathrm{NaBH}_{4}\left[0.1 \mathrm{M}, \mathrm{NaBH}_{4} /\right.$ $(\mathrm{Au}+\mathrm{Pd})(\mathrm{mol} / \mathrm{mol})=5$ ] was then added to form a darkbrown sol. After $30 \mathrm{~min}$ of sol generation, the colloid was immobilised by adding activated carbon (acidified at $\mathrm{pH} 1$ by sulphuric acid) under vigorous stirring conditions. The amount of support material required was calculated so as to have a total final metal loading of $1 \mathrm{wt} \%$ and the molar ratio of $\mathrm{Au}: \mathrm{Pd}$ was varied by adjusting the relative concentrations of the metals in solution. After $2 \mathrm{~h}$ the slurry was filtered, the catalyst washed thoroughly with distilled water (neutral mother liquors) and dried at $120^{\circ} \mathrm{C}$ for $16 \mathrm{~h}$. It should be noted that there are a range of protecting ligands other than PVA that can be used, as well as a range of alternative reducing agents. Variation in the reaction parameters can lead to different particle size distributions and represents an important way of controlling and varying the nature of the nanoparticles that can be obtained. For instance, by co-adding the $\mathrm{Pd}$ and $\mathrm{Au}$ precursors, this
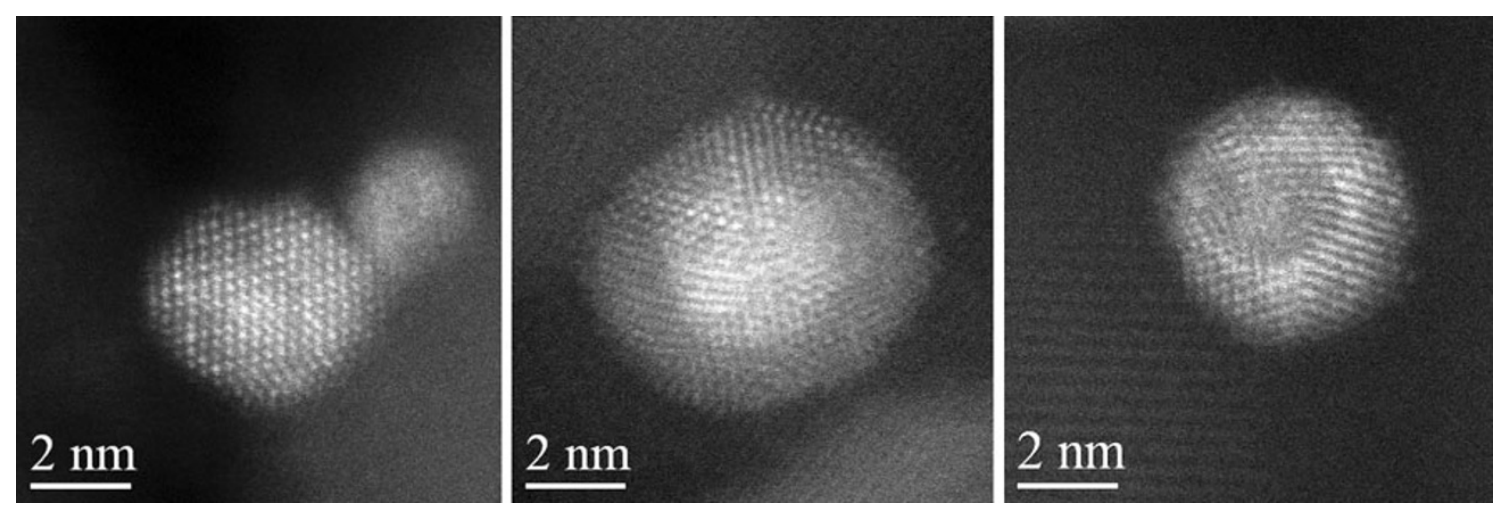

Fig. 1 STEM-HAADF images showing (left) a AuPd homogeneous alloy particles, (middle) a Au-Pd nanoparticle with a gold core and a palladium shell, and (right) a AuPd nanoparticle with a palladium core and a gold shell 


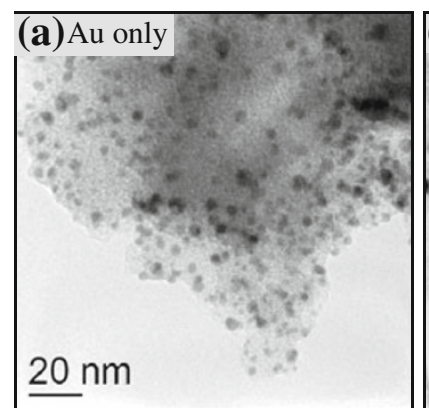

(c) $\mathrm{Au}: \mathrm{Pd}=2: 1$
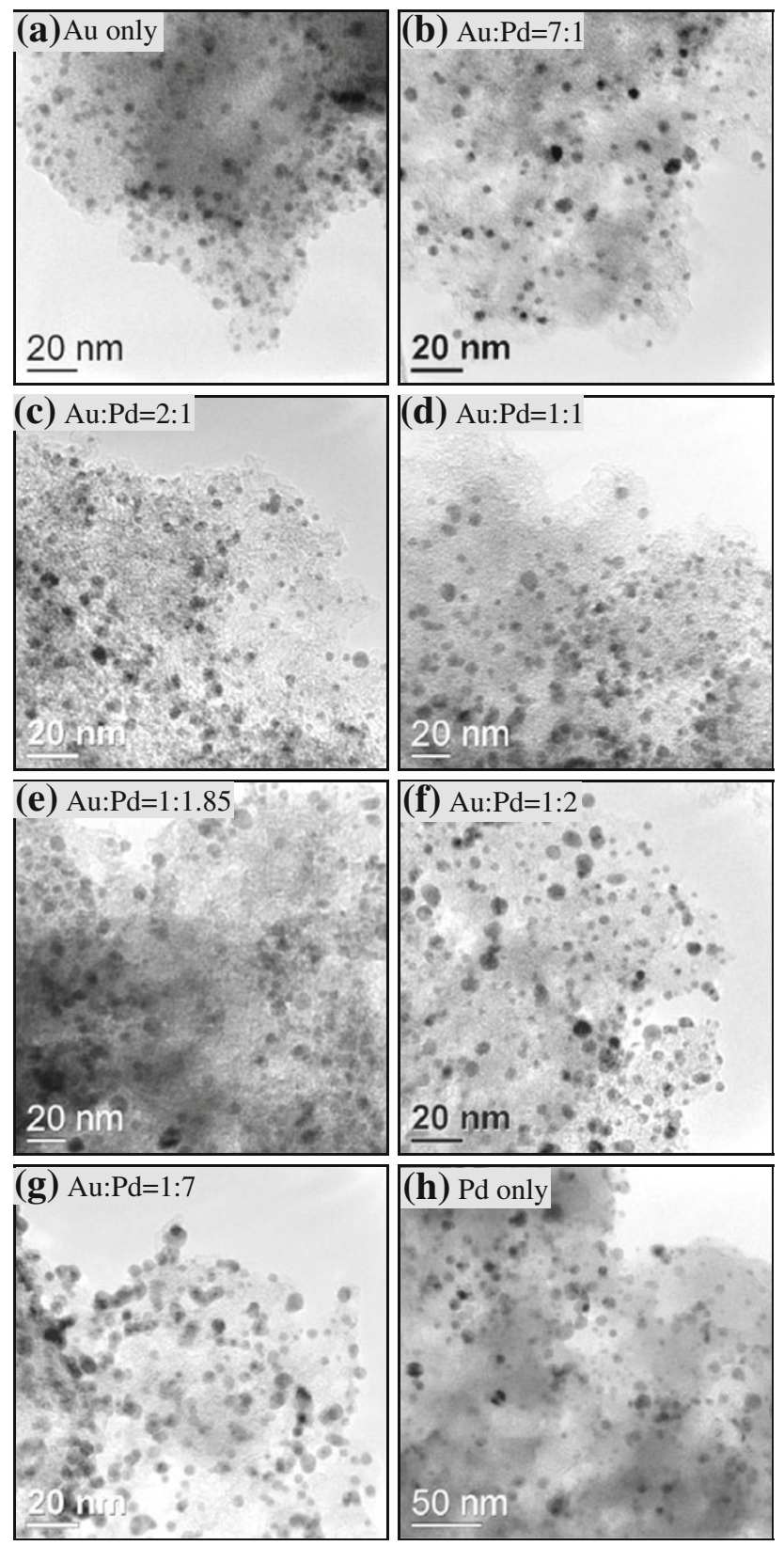

Fig. 2 Representative bright field TEM micrographs showing $\mathrm{Au}-\mathrm{Pd}$ particles immobilised on an activated carbon support: a Au only, b $\mathrm{Au}: \mathrm{Pd}=7: 1$, c $\mathrm{Au}: \mathrm{Pd}=2: 1$, d $\mathrm{Au}: \mathrm{Pd}=1: 1$, e $\mathrm{Au}: \mathrm{Pd}=1: 1.85$, f $\mathrm{Au}: \mathrm{Pd}=1: 2, \mathbf{g ~ A u}: \mathrm{Pd}=1: 7, \mathbf{h}$ Pd only. Reprinted with permission from reference [33]. Copyright (2010) American Chemical Society

method can be used to prepare sol-immobilised Au-Pd nanoparticles that comprise homogeneous alloys. However, by varying the order of addition of these reagents [34] it is possible to prepare nanoparticles that exhibit core-shell structures and examples of these are given in Fig. 1 together with an example of homogeneous $\mathrm{Au}-\mathrm{Pd}$ alloy nanoparticles. The existence of core-shell morphologies is readily discerned due to the inherent $Z$-contrast of the $\mathrm{Au}$ and $\mathrm{Pd}$ in high angle annular dark field (HAADF) STEM images.

\section{Characterisation of sol-immobilised Au, Pd and Au-Pd nanoparticles}

One of the great advantages of the sol-immobilisation method is the flexibility that can be attained with respect to tuning the composition of the alloy nanoparticles. As an example, we prepared a range of $\mathrm{Au}, \mathrm{Pd}$ and $\mathrm{Au}-\mathrm{Pd}$ colloidal sols (Au:Pd $=1: 0,7: 1,2: 1,1: 1,1: 1.85,1: 2,1: 7$, $0: 1)$ by varying the concentrations of the metal salts in the standard preparation method [33]. The reason for carrying out these experiments is that we considered that the active sites for the synthesis of hydrogen peroxide were associated with small nanoparticles that might be comprised mainly of Pd with only a very dilute amount of Au. Hence, by examining a wide range of compositions we could examine this hypothesis in some detail [33]. A set of representative bright field TEM micrographs is shown in Fig. 2 and the particle size distributions of the colloidal metal nanoparticles after immobilisation and drying on an activated carbon support are shown in Fig. 3. The median particles sizes for the monometallic $\mathrm{Au}$ and Pd colloids were found to be 3.5 and $5.4 \mathrm{~nm}$, respectively. The median particle sizes for all the $\mathrm{Au}_{x} \mathrm{Pd}_{y}$ alloys were in the 2.9-4.6 nm range, and did not show any discernable systematic size trend with colloid composition. This shows that the method can be used to make a range of supported nanoparticles which have very similar particle size distribution, but have the potential for widely varying compositions. STEM-HAADF images of the alloy particles in the 2:1, 1:1 and 1:2 Au-Pd samples are shown in Fig. 4. In each case, the metal particles were found to be random homogeneous $\mathrm{Au}-\mathrm{Pd}$ alloys with an f.c.c structure. Energy dispersive X-ray spectra acquired from areas containing $\sim 100$ metal particles showed both $\mathrm{Au}$ and $\mathrm{Pd}$ peaks suggesting intimate mixing of the two elements in the alloy samples. In addition, the relative $\mathrm{Au}$ to $\mathrm{Pd}$ peak areas from the $\sim 100$ particle average spectra qualitatively agreed with the nominal $x$ and $y$ values for each of the $\mathrm{Au}_{x} \mathrm{Pd}_{y}$ alloy compositions. However, it was noticeable that within specific $\mathrm{Au}_{x} \mathrm{Pd}_{y}$ samples, XEDS spectra obtained from individual particles did show considerable composition variations as a function of particle size. This is demonstrated by a set of HAADF images and corresponding XEDS point spectra from particles at the low, median and high ends of the particle size distribution for the Au:Pd (1:7) sample (Fig. 5). Whilst all the particles were homogeneous Au-Pd alloys, the smallest particles were Au-rich, whereas the largest ones tended to be Pd-rich. It is interesting to note that this systematic composition/size trend is diametrically opposite to the situation found for $\mathrm{Au}-\mathrm{Pd}$ nanoparticles prepared by impregnation methods where the larger particles tended to Au-rich and the smaller Pd-rich. 
Fig. 3 Particle size

distributions of the $\mathrm{Au}-\mathrm{Pd}$ particles immobilised on an activated carbon support: a $\mathrm{Au}$ only, b $\mathrm{Au}: \mathrm{Pd}=7: 1$,

c $\mathrm{Au}: \mathrm{Pd}=2: 1, \mathbf{d} \mathrm{Au}: \mathrm{Pd}=1: 1$, e $\mathrm{Au}: \mathrm{Pd}=1: 1.85$,

f $\mathrm{Au}: \mathrm{Pd}=1: 2, \mathbf{g ~ A u}: \mathrm{Pd}=1: 7$, h Pd only. Reprinted with permission from reference [33]. Copyright (2010) American Chemical Society
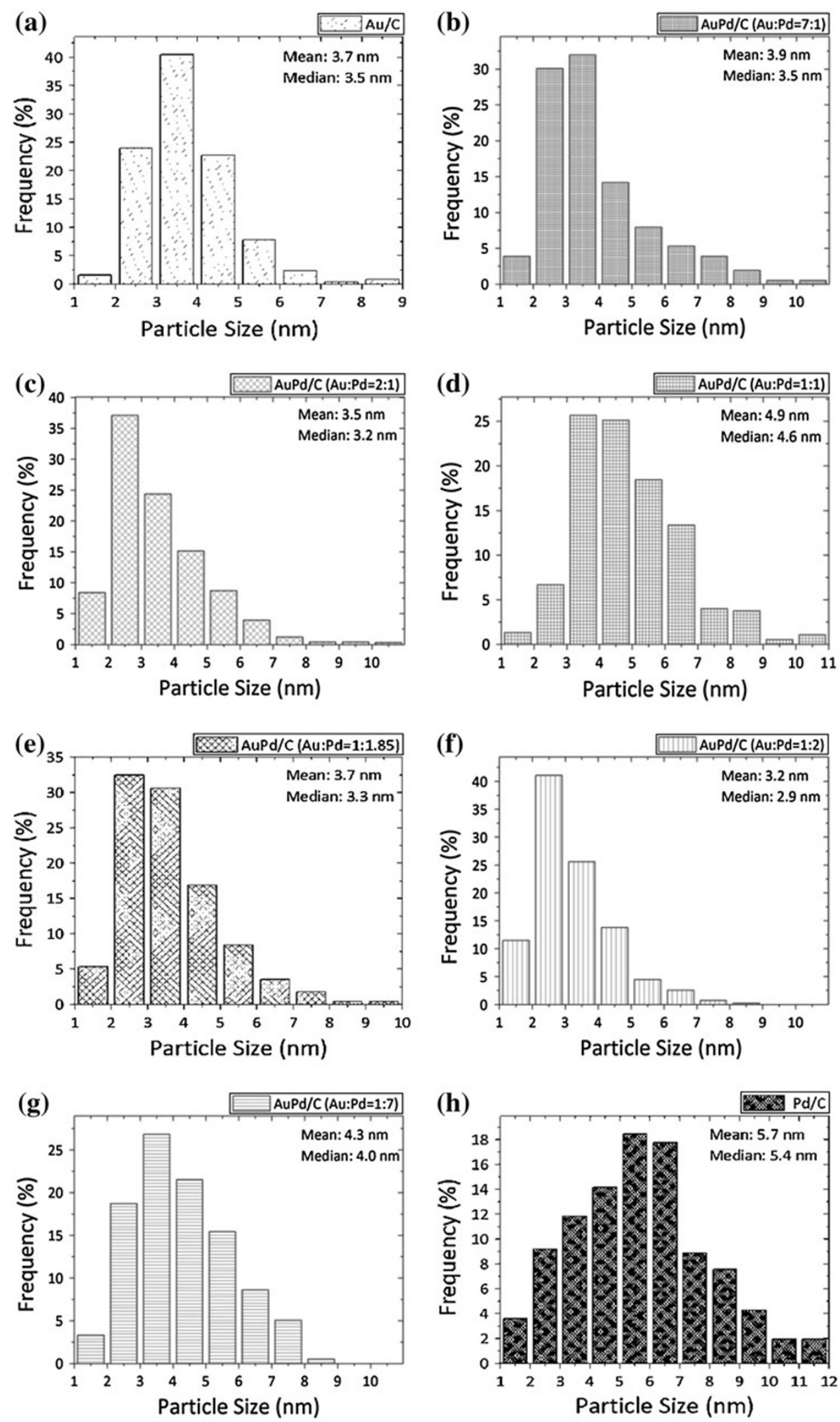

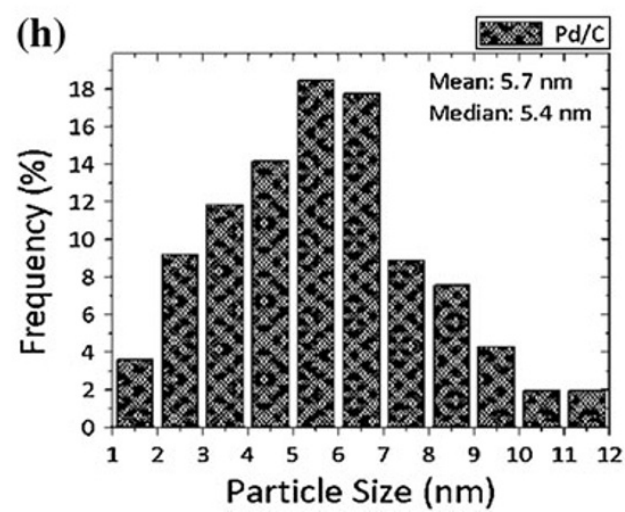


Fig. 4 Representative STEM-HAADF images showing $\mathrm{Au}-\mathrm{Pd}$ homogeneous alloy particles.

a, b $\mathrm{Au}: \mathrm{Pd}=2: 1$,

c, d $A u: P d=1: 1$,

e, f $\mathrm{Au}: \mathrm{Pd}=1: 2$. Reprinted

with permission from reference

[33]. Copyright (2010)

American Chemical Society

$\mathrm{Au}: \mathrm{Pd}$ molar ratio

$2: 1$
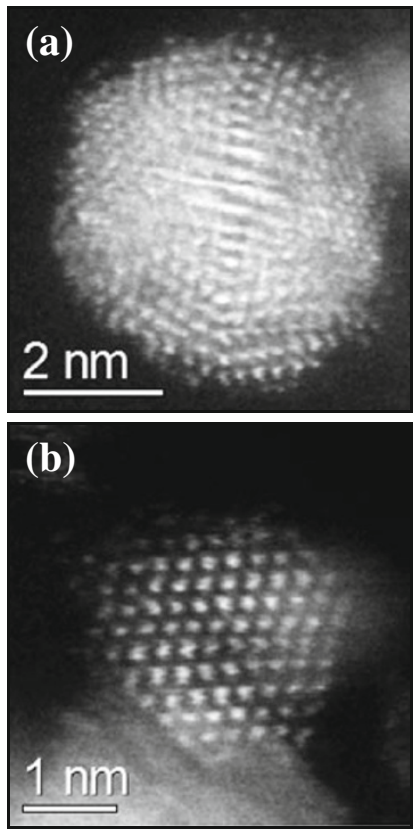

$1: 1$
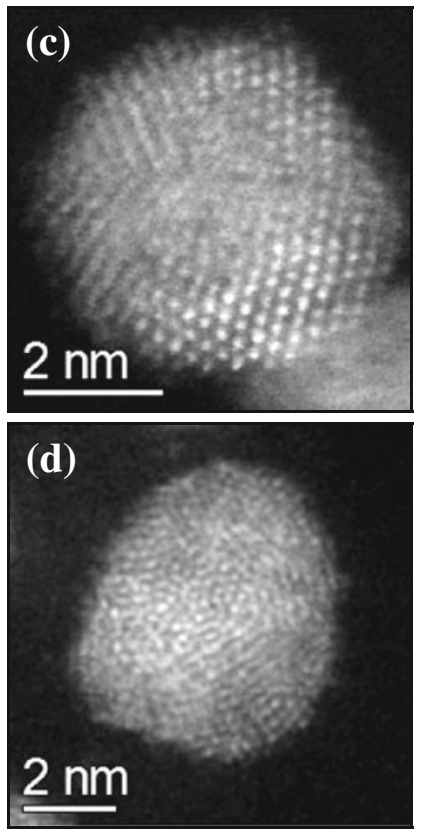

$1: 2$
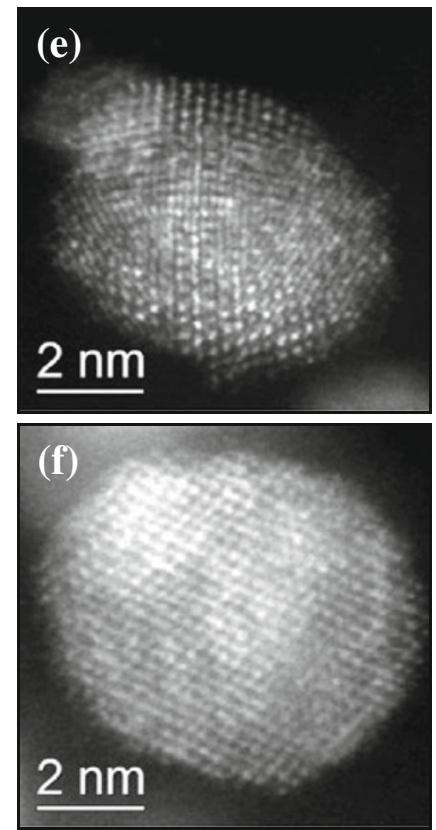

\section{Hydrogen peroxide synthesis and hydrogenation}

The supported $\mathrm{Au}-\mathrm{Pd}$ catalysts were investigated for the direct synthesis of $\mathrm{H}_{2} \mathrm{O}_{2}$ and the results are shown in Fig. 6 [33]. The catalysts were found to be particularly effective for this reaction and the synthesis activity exhibited a maximum at $\mathrm{Au}: \mathrm{Pd}=1: 2$ molar ratio. In our previous studies using catalysts prepared using the impregnation method [16-20] we used an Au:Pd mol ratio of 1:1.85, which is very close to this optimum ratio. However, the catalysts prepared by sol-immobilisation are considerably more active than those prepared using the impregnation method [16-20]. This demonstrates that using the solimmobilisation method we are able to utilise the precious metals much more effectively, as in the impregnation method a significant fraction very large particles are also generated and these have very limited catalytic activity.

In an earlier study [19] we observed that in the catalysts prepared using the impregnation method, the very smallest particles were mainly $\mathrm{Pd}$ and that $3-5 \mathrm{~nm}$ Au-Pd nanoparticles comprised typically $98 \% \mathrm{Pd}$ to $2 \% \mathrm{Au}$. As the activity was considered to be associated with these small particles, this led us to conclude that for optimum activity we needed to find a method to fabricate such particles. However, the results of the sol-immobilised catalysts might suggest that this hypothesis is not necessarily the case, since the Pd-rich Au-Pd colloidal nanoparticles (i.e. $\mathrm{Pd}: \mathrm{Au} \geq 3$ ) actually display a lower productivity than those with a $\mathrm{Au}: \mathrm{Pd}=1: 2$ molar ratio. It must also be taken into account that this effect could also be explained on the basis that the hydrogenation activity of the catalysts is expected to increase with $\mathrm{Pd}$ content and this somewhat cancels out the positive effect of adding $\mathrm{Pd}$ to the $\mathrm{Au}$ nanoparticles for the direct synthesis.

\section{Benzyl alcohol oxidation}

The catalytic oxidation of benzyl alcohol under free solvent conditions is an appropriate model reaction for exploring the catalytic performance of bimetallic Au-Pd catalysts and the results obtained for the conversion of benzyl alcohol to benzaldehyde are shown in Fig. 6. It is found that the catalytic performance in terms of reaction specificity is not dependent on the composition and all catalysts give high selectivities to benzaldehyde which is the primary product. Hence, the main outcome of alloying Au with Pd is to enhance activity. The activity of the monometallic $1 \mathrm{wt} \% \mathrm{Au} / \mathrm{C}$ sample was very poor, but on increasing the $\mathrm{Pd}$ content we observed a progressive increase in catalytic activity. This increase of activity reached a broad maximum with a Au:Pd molar ratio between 1:1 and 1:3. A further increase in the Pd content resulted in a progressive decrease in catalytic activity. It is important to note that even in the presence of a minor amount of gold or palladium (i.e. in the case of 1:7 and 7:1 $\mathrm{Au}: \mathrm{Pd}$ molar ratios) a significant increase in the catalytic activity is observed as compared to the mono-metallic counterparts. It is apparent that the activity profile for benzyl alcohol oxidation has the same dependency on the 

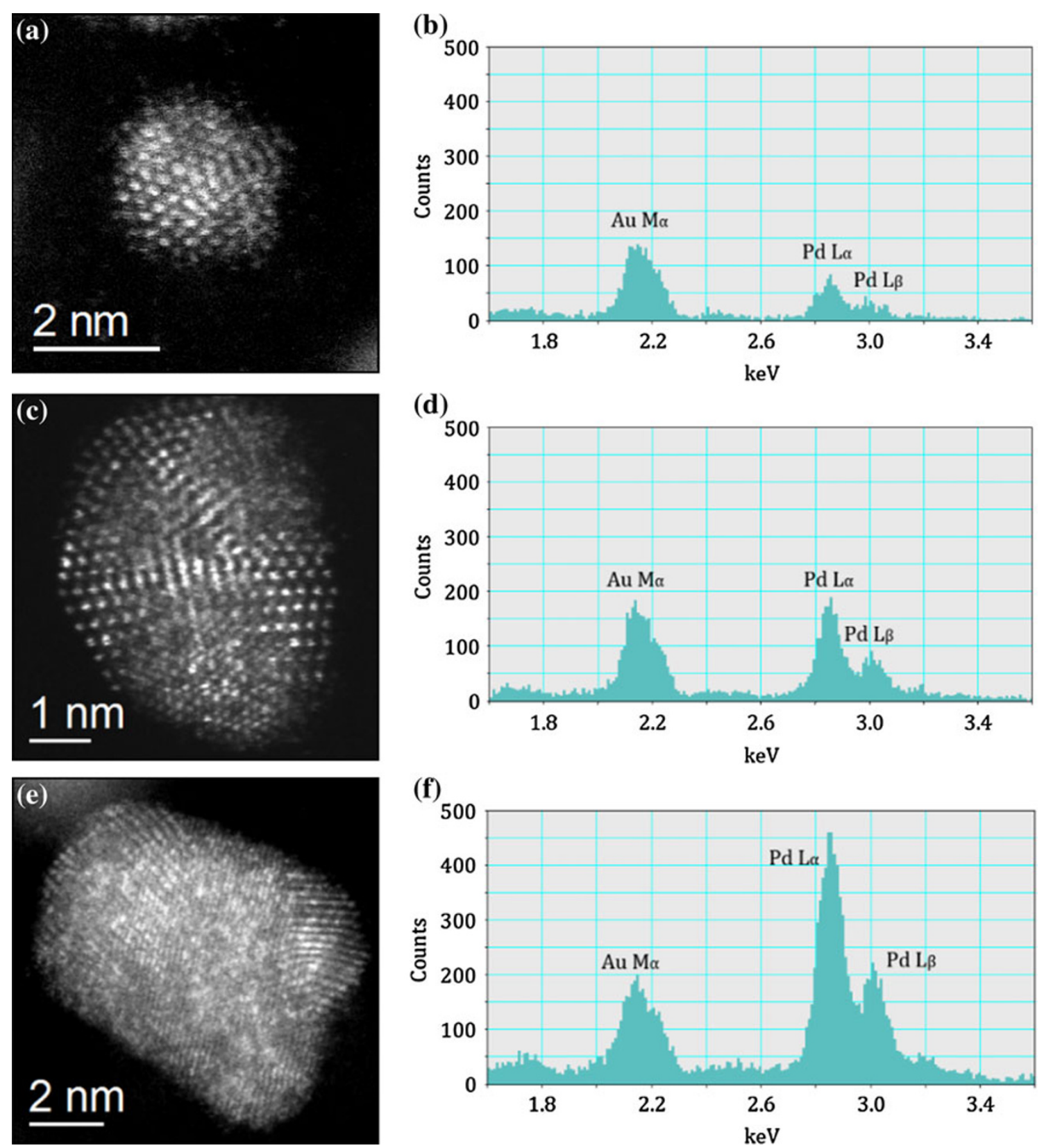

(f)

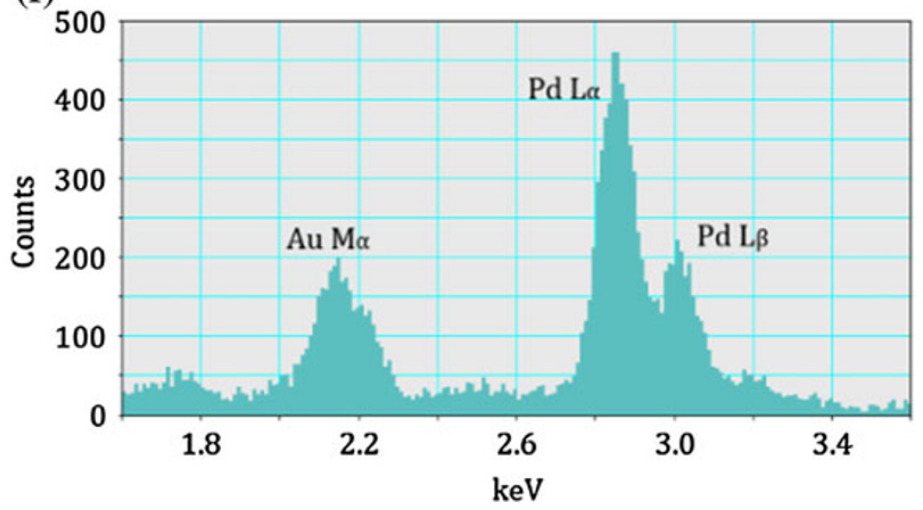

Fig. 5 A set of HAADF images and corresponding XEDS point spectra from particles at the low $(\mathbf{a}, \mathbf{b})$, median $(\mathbf{c}, \mathbf{d})$ and high $(\mathbf{e}, \mathbf{f})$ ends of the particle size distribution for the Au:Pd (1:7) sample. They demonstrate a systematic particle size/composition variation, where the smaller

particles progressively become more Au-rich and Pd-deficient. Reprinted with permission from reference [33]. Copyright (2010) American Chemical Society

Au:Pd molar ratio as does the direct synthesis and hydrogenation of hydrogen peroxide.

\section{Concluding comments}

It is apparent that carbon-supported $\mathrm{Au}-\mathrm{Pd}$ nanoparticles prepared by sol-immobilisation are very effective for the three reactions; namely, the direct synthesis of $\mathrm{H}_{2} \mathrm{O}_{2}$ and its subsequent hydrogenation and the selective oxidation of

benzyl alcohol. For all these reactions we show that the optimum ratio of Au:Pd is ca. 1:1.85. As shown in Fig. 6 the catalytic activity per mol of metal of the Pd:Au series of catalysts for hydrogen peroxide synthesis, hydrogen peroxide hydrogenation and benzyl alcohol oxidation also shows a similar dependence on the Au:Pd molar ratio. This suggests that the active sites for these reactions could be common which is an interesting observation. However, it is also clear that there is considerable variation in the composition of the individual nanoparticles prepared by 
(a)

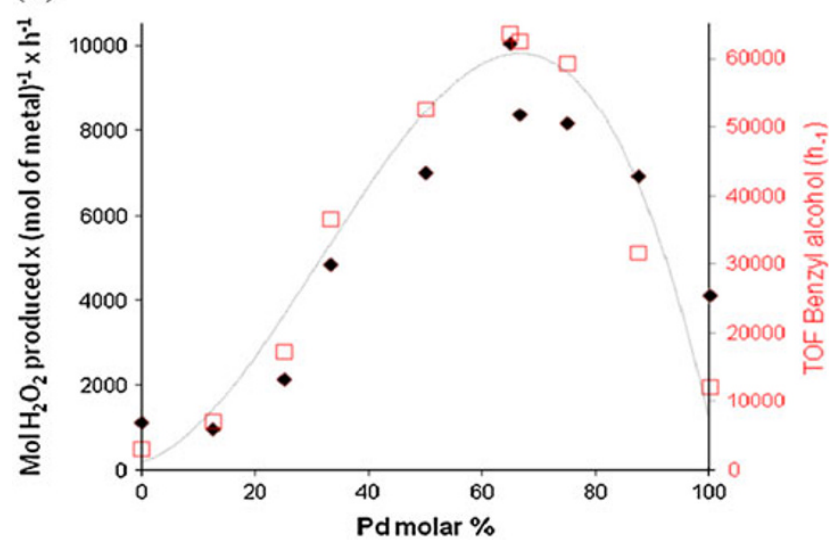

(b)

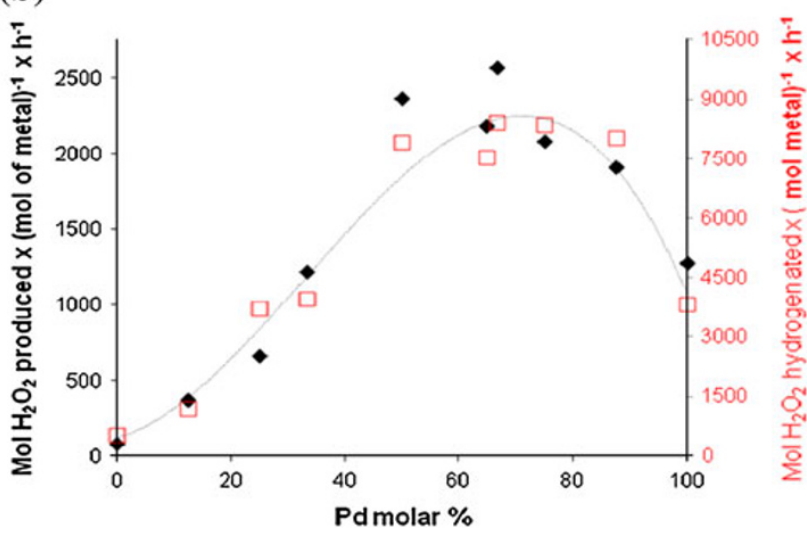

Fig. 6 Specific activity comparison, based on moles of metal present for benzyl alcohol oxidation, for hydrogen peroxide synthesis and hydrogen peroxide hydrogenation with a $1 \mathrm{wt} \% \mathrm{Au}-\mathrm{Pd} / \mathrm{C}$ catalysts prepared by sol immobilisation with $\mathrm{Pd}: \mathrm{Au}$ molar ratio of 1.85 . a Black diamonds $\mathrm{H}_{2} \mathrm{O}_{2}$ productivity calculated after 2 min reaction (left axis), empty squares TOF of benzyl alcohol calculated after 30 min reaction (right axis); b black diamonds $\mathrm{H}_{2} \mathrm{O}_{2}$ productivity calculated after 30 min (left axis), empty squares the rate of $\mathrm{H}_{2} \mathrm{O}_{2}$ hydrogenation calculated after 30 min. Reprinted with permission from reference [33]. Copyright (2010) American Chemical Society

sol-immobilisation and we are now exploring synthetic strategies that will help to overcome this problem since ideally we need to be able to synthesise bimetallic nanoparticles with both uniform particle size distributions and well-defined composition that does not vary from particle-to-particle.

Open Access This article is distributed under the terms of the Creative Commons Attribution License which permits any use, distribution, and reproduction in any medium, provided the original author(s) and the source are credited.

\section{References}

1. Bond GC, Thompson DT (1999) Catalysis by Gold. Catal Rev Sci Eng 41:319-388
2. Bond GC, Thompson DT (2000) Gold-catalysed oxidation of carbon monoxide. Gold Bull 33:41-51

3. Haruta M (2004) Gold as a novel catalyst in the 21st century: preparation, working mechanism and applications. Gold Bull 37:27-36

4. Hashmi ASK (2004) Homogeneous catalysis by gold. Gold Bull 37:51-65

5. Meyer R, Lemaire C, Shaikutdinov ShK, Freund H-J (2004) Surface chemistry of catalysis by gold. Gold Bull 37:72-124

6. Hutchings GJ (2004) New directions in gold catalysis. Gold Bull 37:3-11

7. Hashmi ASK, Hutchings GJ (2006) Gold catalysis. Angew Chem Int Ed 45:7896-7936

8. Haruta M, Kobayashi T, Sano H, Yamada N (1987) Novel gold catalysts for the oxidation of carbon monoxide at a temperature far below $0{ }^{\circ} \mathrm{C}$. Chem Lett 16:405-408

9. Landon P, Ferguson J, Solsona BE, Garcia T, Carley AF, Herzing AA, Kiely CJ, Golunski SE, Hutchings GJ (2005) Selective oxidation of $\mathrm{CO}$ in the presence of $\mathrm{H}_{2}, \mathrm{H}_{2} \mathrm{O}$ and $\mathrm{CO}_{2}$ via gold for use in fuel cells. Chem Commun 3385-3387

10. Landon P, Ferguson J, Solsona BE, Garcia T, Al-Sayari S, Carley AF, Herzing A, Kiely CJ, Makkee M, Moulijn JA, Overweg A, Golunski SE, Hutchings GJ (2006) Selective oxidation of CO in the presence of $\mathrm{H}_{2}, \mathrm{H}_{2} \mathrm{O}$ and $\mathrm{CO}_{2}$ using $\mathrm{Au} / \mathrm{Fe}_{2} \mathrm{O}_{3}$ catalysts for use in fuel cells. J Mat Chem 16:199-208

11. Hutchings GJ (1985) Vapor phase hydrochlorination of acetylene: correlation of catalytic activity of supported metal chloride catalyst. J Catal 96:292-295

12. Sinha AK, Seelan S, Tsubota S, Haruta M (2004) A three-dimensional mesoporous titanosilicate support for gold nanoparticles: vapor-phase epoxidation of propene with high conversion. Angew Chem Int Ed 43:1546-1548

13. Hughes MD, Xu Y-J, Jenkins P, McMorn P, Landon P, Enache DI, Carley AF, Attard GA, Hutchings GJ, King F, Stitt EH, Johnston P, Griffin K, Kiely CJ (2005) Tunable gold catalysts for selective hydrocarbon oxidation under mild conditions. Nature 437:1132-1135

14. Abad A, Conception P, Corma A, Garcia H (2005) A collaborative effect between gold and a support induces the selective oxidation of alcohols. Angew Chem Int Ed 44:4066-4069

15. Corma A, Serna P (2006) Chemoselective hydrogenation of nitro compounds with supported gold catalysts. Science 313:332-334

16. Landon P, Collier PJ, Papworth AJ, Kiely CJ, Hutchings GJ (2002) Direct formation of hydrogen peroxide from $\mathrm{H}_{2} / \mathrm{O}_{2}$ using a gold catalysts. Chem Commun 2058-2059

17. Edwards JK, Solsona BE, Landon P, Carley AF, Herzing A, Kiely CJ, Hutchings GJ (2005) Direct synthesis of hydrogen peroxide from $\mathrm{H}_{2}$ and $\mathrm{O}_{2}$ using $\mathrm{TiO}_{2}$-supported $\mathrm{Au}-\mathrm{Pd}$ catalysts. J Catal 236:69-79

18. Edwards JK, Ntainjua E, Carley AF, Herzing AA, Kiely CJ, Hutchings GJ (2009) Direct synthesis of $\mathrm{H}_{2} \mathrm{O}_{2}$ from $\mathrm{H}_{2}$ and $\mathrm{O}_{2}$ over gold, palladium, and gold-palladium catalysts supported on acid-pretreated $\mathrm{TiO}_{2}$. Angew Chem Int Ed 48:8512-8515

19. Edwards JK, Carley AF, Herzing AA, Kiely CJ, Hutchings GJ (2008) Direct synthesis of hydrogen peroxide from $\mathrm{H}_{2}$ and $\mathrm{O}_{2}$ using supported Au-Pd catalysts. Faraday Disc 138:225

20. Edwards JK, Solsona B, Ntainjua E, Carley AF, Herzing AA, Kiely CJ, Hutchings GJ (2009) Switching off hydrogen peroxide hydrogenation in the direct synthesis process. Science 323:10371041

21. Enache DI, Edwards JK, Landon P, Solsona-Espriu B, Carley AF, Herzing AA, Watanabe M, Kiely CJ, Knight DW, Hutchings GJ (2006) Solvent-free oxidation of primary alcohols to aldehydes using $\mathrm{Au}-\mathrm{Pd} / \mathrm{TiO}_{2}$ catalysts. Science 311:362-365

22. Edwards JK, Hutchings GJ (2008) Palladium and gold-palladium catalysts for the direct synthesis of hydrogen peroxide. Angew Chem Int Ed 47:9192-9198 
23. Hess HT (1995) Hydrogen peroxide. In: Kroschwitz I, HoweGrant M (eds) Kirk-othmer encyclopaedia of chemical engineering, vol 13. Wiley, New York, p 961

24. Henkel H, Weber W (1914) Manufacture of hydrogen peroxide. US Patent 1108752

25. Van Weynbergh J, Schoebrechts JP, Colery JC (1995) Direct synthesis of hydrogen peroxide by heterogeneous catalysis, catalyst for the said synthesis and method of preparation for the said catalyst. US Patent 3265447706

26. Paparatto G, D'Aloisio R, De Alberti G, Furlan P, Arca V, Buzzoni R, Meda L (1999) New catalyst, process for the production of hydrogen peroxide and its use in oxidation processes. EP Patent 0978316A1

27. Zhou B, Lee L-K (2001) Catalyst and process for direct catalytic production of hydrogen peroxide. US Patent 6168775

28. Nystrom M, Wangard J, Herrmann W (2001) Process for producing hydrogen peroxide. US Patent 6210651

29. Lunsford $\mathrm{JH}$ (2003) The direct formation of $\mathrm{H}_{2} \mathrm{O}_{2}$ from $\mathrm{H}_{2}$ and $\mathrm{O}_{2}$ over palladium catalysts. J Catal 216:455-460
30. Dissanayake DP, Lunsford JH (2002) Evidence for the role of colloidal palladium in the catalytic formation of $\mathrm{H}_{2} \mathrm{O}_{2}$ from $\mathrm{H}_{2}$ and $\mathrm{O}_{2}$. J Catal 206:173-176

31. Dissanayake DP, Lunsford JH (2003) The direct formation of $\mathrm{H}_{2} \mathrm{O}_{2}$ from $\mathrm{H}_{2}$ and $\mathrm{O}_{2}$ over colloidal palladium. J Catal 214:113120

32. Choudhary VR, Samanta C, Gaikwad AG (2004) Drastic increase of selectivity for $\mathrm{H}_{2} \mathrm{O}_{2}$ formation in direct oxidation of $\mathrm{H}_{2}$ to $\mathrm{H}_{2} \mathrm{O}_{2}$ over supported $\mathrm{Pd}$ catalysts due to their bromination. Chem Commun 2054-2055

33. Pritchard J, Kesavan L, Piccinini M, He Q, Tiruvalam R, Dimitratos N, Lopez-Sanchez JA, Carley AF, Edwards JK, Kiely CJ, Hutchings $G$ (2010) Direct synthesis of hydrogen peroxide and benzyl alcohol oxidation using Au-Pd catalysts prepared by sol immobilization. J Langmuir 26:16568-16577

34. Herzing AA, Watanabe M, Kiely CJ, Edwards J, Conte M, Tang ZR, Hutchings GJ (2008) Aberration corrected analytical electron microscopy studies of bimetallic nanoparticles. Faraday Discuss 138:337-351 